\title{
América Latina en las aguas agitadas de la multipolaridad del orden mundial emergente. Politica ygeopolítica regional (2000-2018)
}

\author{
Alberto Rocha \\ Universidad de Guadalajara \\ albertorochav@yahoo.com.mx
}

\begin{abstract}
RESUMEN
ALC se mantuvo vinculada al orden continental americano y panamericano durante todo el orden internacional bipolar, desde 1945 hasta 1990/91. Cuando se cayó este orden internacional bipolar, debido a la implosión de la URSS, los EE.UU. diseñaron e impulsaron el orden unipolar de Post Guerra Fría, que se extendió hasta el año 2016. Y ALC, en un primer momento, se mantuvo articulada al orden continental americano y panamericano $y$, en un segundo momento, a partir de fines de los años noventa, comenzó a distanciarse y autonomizarse de los EE.UU. Así, desde el año 2000 hasta los años 2015/16, la región fue gobernada mayoritariamente por presidentes progresistas, lo que le permitió ganar mayor autonomía y cohesionarse (gracias a un despliegue importante de su proceso de integración regional) dando pasos importantes hacia la configuración de un orden regional latinoamericano y caribeño (articulado a Asia Pacífico), cuya expresión máxima fue la fundación y puesta en marcha de la CELAC y del Foro China-CELAC, Fueron 15 años muy importantes para la región. Pero, esta situación comenzó a cambiar rápidamente con la llegada de los gobiernos conservadores y neoliberales en la región y también con el arribo de $\mathrm{D}$. Trump, un gobierno conservador y supremacista en los EE.UU. Es así como se abre la transición multipolar hacia un nuevo orden mundial. En consecuencia, ALC vuelve a rearticularse con el orden continental americano y (neo) panamericano: relaciones geopolíticas con los EE.UU., reactivación de la OEA y relanzamiento de la Doctrina Monroe. Las relaciones "carnales" de los gobiernos conservadores de la región con los EE.UU. van viento en popa. Pero, en esta nueva relación geopolítica el gobierno norteamericano solamente dispone de armas y tropas para promover cualquier invasión de países rebeldes. En esta nueva relación no hay dinero para la cooperación con los países de la región. Entonces, la geoeconomía de los gobiernos conservadores y neoliberales sigue su movimiento hacia China y Asía Pacífico. Así, la geo política va hacia Norteamérica y los EE.UU, y la geoeconomía fluye hacia Asía Pacífico y China, esto es una verdadera "esquizofrenia".
\end{abstract}

PalABRAS CLAVE: Multipolaridad, América Latina, geopolitica regional. 


\title{
Latin America in the rough waters of the multipolarity of the emerging world order.Politics and regional geopolitics (2000-2018)
}

\begin{abstract}
Latin America and the Caribbean (LAC) remained linked to the American and Pan-American continental order throughout the bipolar international order, from 1945 to 1990/91. When this bipolar international order fell, due to the implosion of the USSR, the US designed and promoted the Post Cold War unipolar order, which lasted until 2016. LAC, at first, remained articulated to the American and Pan American continental order and, in a second moment, from the end of the nineties, began to distance itself and become autonomous from the USA. Thus, from 2000 until 2015/16, the region was governed mainly by progressive presidents, which allowed it to gain greater autonomy and cohesion. Thanks to an important deployment of its regional integration process, LAC took important steps towards the configuration of a Latin American and Caribbean regional order (articulated to the Asia Pacific), which crystallized in the foundation and start-up of CELAC and the China-CELAC Forum. These 15 years were very important for the region, but, this situation began to change rapidly with the arrival of conservative and neoliberal governments in the region and also with the arrival of $D$. Trump, a conservative and supremacist government, in the US. This is how the multipolar transition opens towards a new world order. As a result, LAC rearticulates with the American and (neo) PanAmerican continental order: geopolitical relations with the US, reactivation of the OAS and relaunch of the Monroe Doctrine. The conservative governments of the region are strenthening their "carnal" relations with the USA. But, in this new geopolitical relationship, the US government only offers weapons and troops to promote invasion of rebel countries. In this new relationship there is no money for cooperation with the countries of the region. So, the geoeconomy of the conservative and neoliberal governments continues its movement towards China and the Asia Pacific. Thus, geopolitics looks towards North America and the US, and geoeconomy flows to the Asia Pacific and China, this may be called a true "schizophrenia".
\end{abstract}

KEYWORDS: Multipolarity, Latin America, regional geopolitics.

\section{Introducción}

os cambios políticos y geopolíticos que se plasmaron en nuestra región con los gobiernos progresistas (desde el año 2000 hasta el 2015) no fueron pasajeros y superficiales sino expresiones fuertes de un proceso geopolítico regional orientado hacia la participación en la configuración de un nuevo orden mundial propuesto y promovido por los BRICS (las potencias regionales-globales). Lo extraordinario fue que el orden regional naciente se encontraba articulado al nuevo orden mundial emergente en Euro-Asia y Asia Pacífico.

Los gobiernos progresistas de ALC orientaron fundamentalmente la dinámica regional y los procesos de integración regional (CELAC, MERCOSUR, CARICOM, UNASUR, ALBA....) en una perspectiva geopolítica SUR-SUR, buscando relacionarse con los BRICS y, sobre todo, con China, Rusia e India, que además son los líderes de este 
foro geopolítico y también de la Organización de Cooperación de Shanghái-OCS. Es decir, buscaron articularse con el ascenso de las nuevas potencias mundiales y con el proceso de conformación del nuevo centro de la economía mundial impulsado por el proyecto OBOR (One belt one Road) en Euro-Asia y Asía Pacífico.

Todo indica, entonces, que se estaba constituyendo, con los gobiernos progresistas, un nuevo orden regional vinculado al orden mundial emergente. Por eso la región se movió y dinamizó fuertemente en esa perspectiva durante 15 años y, además, se buscó la relación geoeconómica y geopolítica con ellos y se propició la presencia tanto de China como de Rusia.

Hasta el año 2015 los gobiernos progresistas, específicamente la primera generación de gobiernos progresistas, aportaron todo lo que pudieron. Desde el año 2016, con el impeachment y destitución de Dilma Rousseff (promovido por las fuerzas políticas neoliberales y conservadores), el proceso progresista habría sido impactado en Brasil, el país que se convirtió en el laboratorio del progresismo con el liderazgo del presidente Lula da Silva. Desde entonces, con toda claridad, se habría iniciado el proceso de reinversión del movimiento socio-político progresista (cuyo símbolo es el encarcelamiento del ex Presidente Lula da Silva) y el declive de los gobiernos progresistas en toda la región.

En la actualidad, estamos viviendo una suerte de restablecimiento de un conservadurismo neoliberal (Brasil, Argentina, Chile, Paraguay, Ecuador, Colombia, Perú, Honduras, El Salvador...) y una rearticulación subordinada con la superpotencia declinante de Norteamérica. Esto es, por un lado, se estaría revirtiendo el proceso de creación de un nuevo orden regional, articulado con el nuevo orden mundial emergente impulsado por los BRICS y, por otro lado, se pretendería restablecer la articulación con el orden continental americano y (neo)panamericano que se encuentra en plena decadencia. Y, es por esto que EE.UU. y el gobierno de D. Trump están de regreso y actuando con todo su poder político-militar en la región.

Ya en pleno año del 2019, es más que evidente que la estrategia política y geopolítica estadounidense en América Latina y Caribe fue y todavía sigue: promover el surgimiento de gobiernos conservadores (aunque sea de extrema derecha y prefascista como el de Jair Bolsonaro en Brasil), desprestigiar-desestabilizar-desactivar (impeachment, golpe parlamentario y destitución) al gobierno progresista de la primera potencia regional latinoamericana (cabeza del progresismo y miembro del BRICS), paralizar la CELAC (el foro político diplomático regional cabeza del proceso de autonomización regional), promover la formación del Grupo de Lima (un grupo de países totalmente subordinado a los Estados Unidos), continuar desestabilizando y cercando política y diplomáticamente a algunos gobiernos progresistas de primera 
generación como Venezuela y Nicaragua (que se han tornado bastante autoritarios), continuar con el bloqueo de Cuba (un verdadero acto de violación permanente de soberanía nacional ), ensayar intervenciones militares (como la que se practica contra Venezuela) y, finalmente, intentar cortar los lazos geoeconómicos-geopolíticos de la región con China y Rusia.

$Y$, lo más grave de esta estrategia es que se ha vuelto a desempolvar la nefasta Doctrina Monroe con su postulado del "patio trasero".

Como hemos podido ver, la dinámica geopolítica de la región se encontraba estrechamente relacionada con la nueva dinámica geopolítica mundial, sobre todo desde el año 2000 hasta finales del 2015. Aunque debemos anotar que esta nueva dinámica geopolítica mundial data de inicios de los años noventa, cuando un grupo de países semiperiféricos (los BRICS) y una región (Asia Pacífico) emprenden su ascenso.

Por ello es que formulamos dos preguntas que se encuentran muy relacionadas:

¿Por qué en los años noventa, después de la Guerra Fría y la Bipolaridad, la apuesta estadounidense para crear un nuevo orden unipolar, occidental u neoliberal terminó dando lugar a un proceso de generación de un orden mundial euroasiático?

¿Cómo ALC al mantenerse distante de la apuesta estadounidense por un orden occidental-unipolar neoliberal terminó vinculándose con el proceso de generación de un orden mundial euroasiático?

Indudablemente, la primera pregunta no es la principal en nuestro trabajo, pero sin una respuesta adecuada sobre ella no será posible abordar la segunda pregunta, que sí es la central y respecto de la cual se harán los mayores desarrollos.

\section{El orden mundial de Guerra Fría (1945-1990) y de Post Guerra Fría (1990-2015)}

En este apartado buscamos esclarecer la cuestión del orden mundial de Guerra Fría y de Post Guerra Fría, para que más adelante podamos establecer la relación de ALC con el orden de Guerra Fría y de Post Guerra Fría.

\subsection{El orden internacional}

Antes de iniciar los desarrollos de este primer importante tema, será preciso presentar nuestra concepción del orden internacional, aunque sea de manera resumida. Veamos el esquema que sigue: 


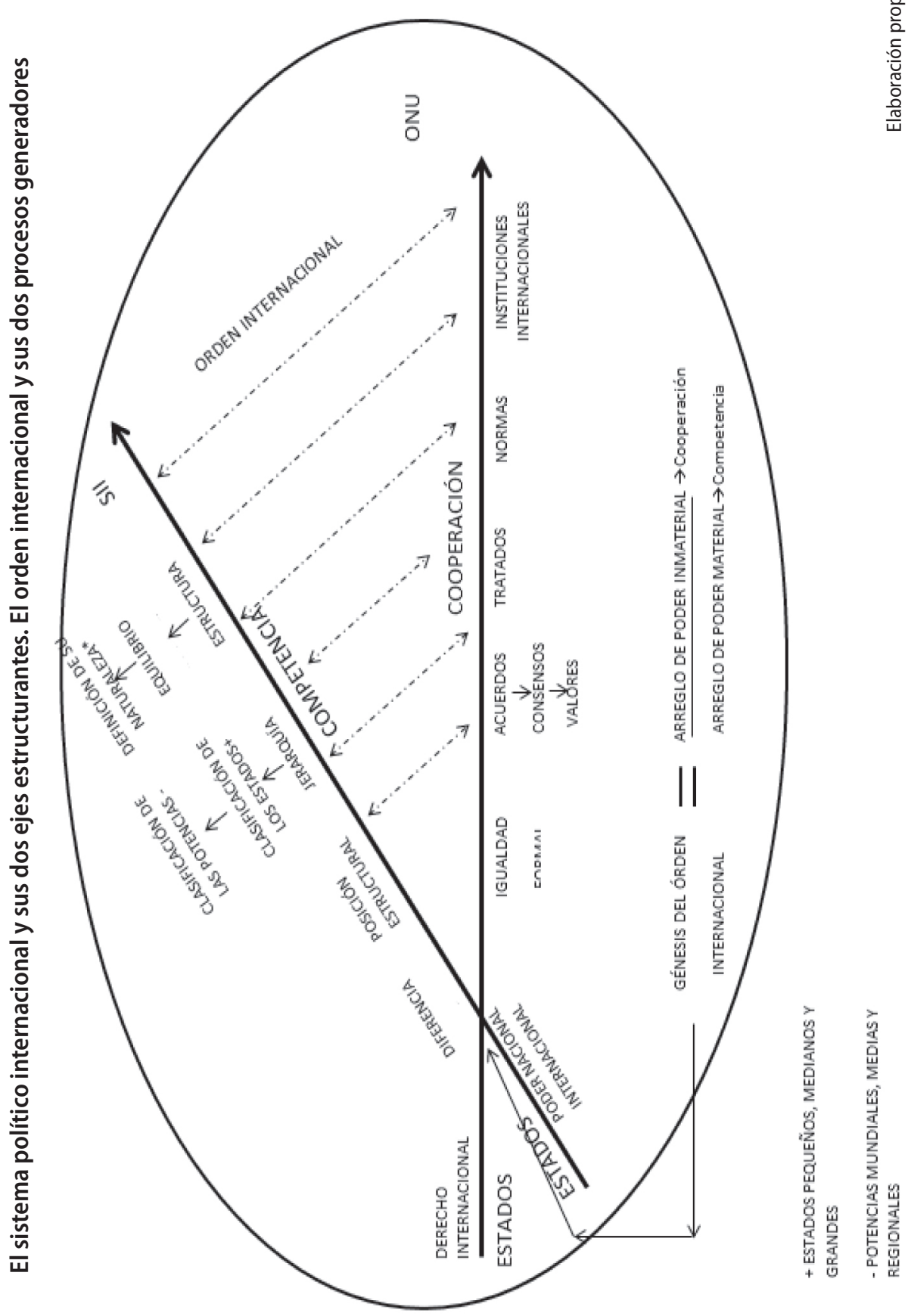

Revista de Sociología 29(2019):113-159 | https://doi.org/10.15381/rsoc.v0i29.16977 
Muy bien, sobre el orden internacional y sistema político internacional anotaremos algunos desarrollos en nueve puntos:

1. El orden internacional-Ol es un patrón de organización, dinamización y relacionamiento de los Estados en el sistema interestatal y en la Organización de las Naciones Unidas, es decir en la Comunidad Internacional (esta definición recoge algo de los aportes de Hedley Bull: 2005).

2. El Ol es el resultado de la convergencia de dos procesos: un arreglo de poder material (capacidades, poder, posición estructural, jerarquía y estructura) y un arreglo de poder inmaterial (acuerdos, tratados, normas instituciones) (aquí también recogemos parcialmente los desarrollos de John lkenberry: 1996).

3. Estos dos procesos aportarán cada uno elemento para la conformación de ese "patrón" que condicionará la manera en que los Estados se organicen, dinamicen y relacionen. Los dos elementos son la competencia y la cooperación.

4. El Ol dispone desde su génesis que los Estados tienen que competir y cooperar, pues si no lo hacen podrían quedar marginados. Así, mientras más compiten los Estados menos cooperan; y mientras más cooperan menos compiten.

5. Estos dos elementos (la competencia y la cooperación), al momento de definir la naturaleza contradictoria del patrón, van a la vez a condicionar la formación de la estructura del sistema político internacional-SPI a partir de dos ejes, de manera que un eje es el de la diferencia real y jerarquía (en términos de poder nacional-internacional) y el otro eje es el de la igualdad formal y semejanza (según las normas del derecho internacional). En el primer eje se constituye y juega la autonomía de los Estados. En el segundo eje se define y ejerce la soberanía de los Estados. Autonomía (la dimensión real) y soberanía (la dimensión formal) se relacionan estrechamente entre sí.

6. El primer eje es el sustento de conformación del sistema interestatal internacional-SIl y el segundo eje es la base para la constitución de la Organización de las Naciones Unidas-ONU. Por lo tanto en el Sll se compite abiertamente (hasta las últimas consecuencias: ascenso, conflicto, confrontación y guerra; constitución de potencias internacionales y definición de polos mundiales) y en la ONU se busca cooperar insistentemente (hasta donde sea posible: diálogo, respeto de la soberanía estatal, paz, seguridad colectiva y bienestar internacional; también la implementación de una gobernabilidad-gobernanza modelada por las potencias mundiales).

7. Entonces el SPI Modelo de Naciones Unidas, queda conformado por dos estructuras contradictorias, sin límites claros, articuladas y compenetradas, donde la dinámica del sistema interestatal es muy fuerte y la dinámica del sistema de 
Naciones Unidas es débil. Más todavía la dinámica del SIl condiciona la dinámica de la ONU y se despliega dentro de ella. Un ejemplo muy revelador es la presencia permanente de las potencias mundiales en el Consejo de Seguridad.

8. De esta manera, la comprensión del Ol es decisivo para mejor entender la estructuración y funcionamiento del SPI. Así, es fundamental entender que todo orden internacional es el resultado de una génesis histórica y tiende a desenvolverse en un largo plazo (el SPI Modelo de Westfalia y el SPI Modelo de Naciones Unidas, tal como entiende David Held: 1997). De esta manera, queda claro que la primera guerra mundial no produjo un orden internacional nuevo, razón por la cual la Sociedad de Naciones fue débil y caótica. En cambio, la ONU fue y es un poco más resistente, a pesar de las contradicciones internas que la atraviesan debido al permanente desafío del interés internacional por el interés nacional de los Estados.

9. Desde 1945 hasta 1990 se estableció un orden mundial bipolar, como resultado de las dos guerras mundiales y del proceso de paz acordado. Este orden se terminó en 1990. La llamada unipolaridad en el SPI de Post Guerra Fría (19902016) no logró plasmarse como un nuevo orden internacional, pues solamente fue una extensión unilateral del orden particular occidental impulsado por los Estados Unidos (después de la caída del orden particular oriental) mientras los Estados se restablecían después del choque que significó la implosión y caída de una de las superpotencias (la URSS), la finalización de la Guerra Fría y de la bipolaridad mundial.

10. Es sumamente importante saber que el orden internacional general de Guerra Fría se basa en dos órdenes internacionales parciales: el de Occidente y el de Oriente, ambos constituidos alrededor de un polo, los EE.UU. y la URSS, respectivamente. Pero, también es importante conocer que el orden internacional general reposa, además, sobre ordenes continentales y regionales.

\subsection{El sistema político internacional y la bipolaridad mundial}

Estamos en el SPI -modelo naciones unidas, de acuerdo con D. Held. Y lo primero que habría que anotar es que la Segunda Guerra Mundial sí permitió la formación de una nuevo orden mundial, diferente del orden mundial westfaliano instaurado en 1648 después de la Guerra de los Treinta Años y con la firma del Tratado de Westfalia. La firma del Tratado de San Francisco (1945), como ya lo anotamos, fue la resultante de una arreglo de poder material y un arreglo de poder inmaterial, lo que permitió que se constituyera un SPI estructurado en dos ejes: el eje interestatal 
bipolar y de Guerra Fría y el eje de las Organización de las Naciones Unidas-ONU. Bien entendido, como el segundo eje es una variable dependiente del primer eje, los Estados más fuertes y, sobre todo, las potencias mundiales condicionan fuertemente el desempeño de la ONU, puesto que esta organización es de naturaleza internacional e intergubernamental, es decir las decisiones en sus órganos principales las toman los Estados. Dicho de otra manera, la bipolaridad mundial y la Guerra Fría habrían condicionado fuertemente el desempeño de la ONU:

Aquí solamente trataremos de plasmar algunas anotaciones necesarias sobre la estructuración bipolar del SIl y la Guerra Fría. Como resultado de la Segunda Guerra Mundial la naturaleza de la estructura del SII resulta bipolar: basada en dos superpotencias, los EE.UU. y la URSS. Esto es, el orden general internacional reposa sobre dos polos internacionales y de alcance mundial. Pero, este orden general es uno y dos a la vez, pues cada polo se constituye en el centro de dos órdenes semigenerales: el orden liberal occidental y el orden socialista oriental. De esta manera, se sanciona un reparto del poder en el mundo entre las dos superpotencias, lo que les permitía a cada superpotencia ejercer supremacía, hegemonía y liderazgo en sus respectivos órdenes semi-generales.

Finalmente, habrá que anotar que los dos polos del orden general, coexistieron de manera tensa, es decir, compitieron y confrontaron permanentemente en términos, económicos, tecnológicos, políticos. culturales y militares, dando lugar a lo que se llamó Guerra Fría. Y, como ya conocemos, una superpotencia, un polo y un semi-orden internacional ganó está contienda que duró casi medio siglo.

\subsection{El sistema político internacional de Post Guerra Fría y la apuesta estadounidense por la unipolaridad}

En este apartado, también presentaremos un resumen bastante apretado de este periodo llamado de Post Guerra Fría. Bien, el llamado periodo de Post Guerra Fría-PGF fue presentado por los analistas estadounidenses como el inicio de la conformación de una nuevo SPI, de un nuevo orden internacional y de un solo polo mundial. EI SPI de PGF sería el comienzo de algo nuevo, el orden internacional naciente se presentaba como unipolar, donde el flamante y único polo era la superpotencia norteamericana. Todo este relato tomó forma y se proyectó al mundo durante los gobiernos de George H.W Bush (1989-1992), Bill Clinton (1993-2000), George W.Bush (2000-20008) y Barack Obama (2008-2016).

Primer Momento (G. H.W Bush), se canta y festeja la supuesta victoria sobre las cenizas del Bloque de Estados Socialistas y de la URSS. Aquí solamente dos co- 
mentarios. La deriva autoritaria del socialismo terminó dando lugar al socialismo real y estaliniano. Estas fue la causa mayor de su colapso y, por lo tanto, no lo fue la estrategia de contención estadounidense. El error de los EE.UU. y de las potencias Occidentales fue haber transformado a la Unión Soviética y a los Estados socialistas del Este en sus enemigos geopolíticos y geoestratégicos. Otra situación se habría experimentado y vivido si el mundo de pos guerra hubiera sido plural y tolerante.

Segundo momento (dos gobiernos de Clinton), los EEUU. emprenden decididamente la extensión del orden parcial occidental hacia todo el mundo y se ensaya el orden unipolar: se mantiene la alianza atlántica (EE.UU. e Inglaterra), se impulsan procesos de occidentalización y liberalización, se establecen pactos políticos, alianzas militares y tratados comerciales y se busca difundir en el mundo un conservadurismo neoliberal extrovertido (o globalizante). Este es un proceso de expansión occidental y de construcción de un orden unipolar en base a la única superpotencia y las demás potencias occidentales.

Tercer momento (dos gobiernos de Bush Jr. 2001), se continúa con el proceso de expansión occidental y el ensayo unipolar, pero ahora con matices fuertemente militaristas. Entonces comienza la resistencia creciente de las potencias regionales y sobre todo de los BRICS. Los gobiernos estadounidenses no valoraron correctamente el proceso que tomó curso con los Estados semiperiféricos en la década de los años noventa del siglo pasado; es más lo menospreciaron. Pues bien, varios de estos Estados semiperiféricos se convirtieron en potencias regionales y algunas de ellas formaron el Foro BRICS. Es así como la unipolaridad será desafiada por la resistencia creciente de los BRICS (Brasil, Rusia, India, China y Sudáfrica), quedando en la escena internacional el G-7 ante el G-5 (como dos actores importantes de la política internacional) y el conservadurismo neoliberal extrovertido frente al nacionalismo neodesarrollista progresivo.

Cuarto momento (dos gobiernos de Obama), se inicia el proceso de contención de las cabezas de los BRICS (China y Rusia) y se trata de desactivar a algunas potencias regionales. Es así como desde finales del primer mandado y, sobre todo, durante el segundo mandato de Obama se diseñan e implementan las dos estrategias de contención de China y Rusia: el Tratado Transpacífico y el Tratado transatlántico. Y también en ALC se impulsa el proceso de desactivación de la potencia regional BRICS, es decir Brasil y, de alguna manera, de Argentina, en tanto potencia regional secundaria. Y, no dejaremos de anotar, que una vez más los gobernantes de la superpotencia cometen el error de transformar a los BRICS y especialmente a China y Rusia como sus enemigos estratégicos. Ahora ya no hay argumentos impactantes, como la "amenaza comunista", quedando solamente la verdad desnuda: China y 
Rusia no son solamente potencias regionales sino nuevas potencias mundiales que traen consigo otro proyecto de orden mundial. Y, claro está, la superpotencia no está dispuesta a incursionar pacífica y cooperativamente en este proyecto nuevo de orden mundial.

\section{D. Trump (2017): el fin de la unipolaridad y el inicio de la multipolaridad}

Con el arribo al gobierno de D. Trump se termina y cierra la etapa de Post Guerra Fría y con ello finaliza la secuela unipolarista impulsada por los Estados Unidos. La Post Guerra Fría no ha sido más que una etapa de salida de la llamada Guerra Fría, donde la superpotencia triunfante y las potencias aliadas occidentales pretendieron expandirse al mundo entero - el Bloque de países socialistas y la URSS siempre fue un obstáculo mayor para lograr tal despliegue-

Esta expansión se sustentaba en el proyecto de unipolaridad de los EE.UU., es decir la superpotencia reinando sola en la cúspide de la jerarquía interestatal mundial y transformando el orden parcial occidental (que fue el más grande) en un nuevo orden mundial para el mundo del siglo XXI —EI Nuevo Siglo Americano (o mejor llamarlo el trasnochado sueño americano)—. D. Trump, que llega al gobierno estadounidense, desde los márgenes del establishment republicano y del establishment neoliberal republicano-demócrata, con su ideología conservadora, neonacionalista, proteccionista, antineoliberal y supremacista, desbarata la etapa de la Post Guerra Fría y manda al traste la unipolaridad.

D. Trump abre completamente una situación nueva en el mundo: la transición hacia una multipolaridad mundial y posiblemente hacia la conformación de un nuevo sistema político internacional. Pero hay algo que queda plenamente revelado en este nuevo escenario mundial: la superpotencia se encuentra en declive, esto es en pleno proceso de descenso.

Es así, como comienza la competencia abierta entre EE.UU. (la superpotencia declinante) con China y Rusia (las dos grandes potencias internacionales ascendentes). Trump impulsa diversas sanciones de contención contra Rusia y una guerra comercial contra China. China y Rusia cooperan mutuamente y establecen diversos tipos alianzas político-militares. Además estas dos potencias regionales-globales mantienen buenas relaciones de cooperación con India (a pesar de las tensiones entre India y China). No olvidemos que China, Rusia e India no solamente son miembros del BRICS sino también de la Organización de Cooperación de Shanghai, además de que China y Rusia son los principales Estados impulsores de la Nueva 
Ruta de la Seda. De esta manera, el despliegue geoeconómico y geopolítico mundial de China (sobre todo) y de Rusia es muy notable.

De esta manera se inicia el proceso de transición hacia la formación de un nuevo orden mundial y de un nuevo sistema político internacional; siendo estos procesos abiertos e interdependientes. En cuanto al nuevo orden no se pueden avanzar predicciones: unipolaridad, bipolaridad, tripolaridad. Lo que sabemos es que en esta transición tenemos una multipolaridad dinámica y tensa. Y sobre la ONU, lo único que podemos decir es que su reforma dependerá de cómo quede arreglado el nuevo orden internacional. Aquí dejo anotado que no estamos incluyendo en el análisis las variables de la globalización y de la regionalización del nuevo mundo emergente.

Así pues, la vorágine de sucesos que se desencadenan desde 2017 en el mundo impactarán directamente en $\mathrm{ALC}$, puesto que nuestra región se está convirtiendo o ya quedó establecida como un espacio de competencia inter-hegemónica entre EE.UU., China y Rusia (en menor medida).

En la Gráfica de abajo se puede observar la competencia abierta entre las potencias mundiales y las potencias regionales-globales.

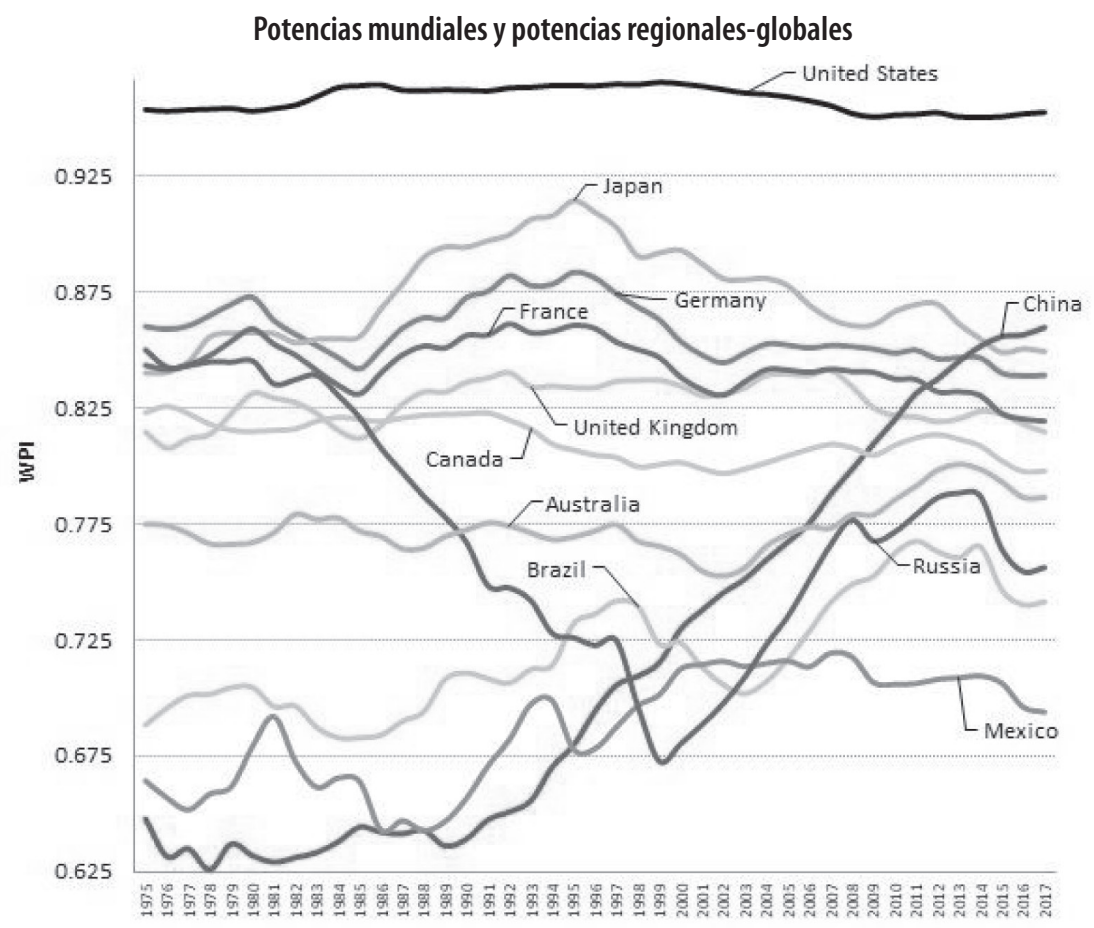

Fuente: Base de datos para el Índice de Poder Mundial https://wordpress.com/view/ integraciongobernabilidadydesarrolloalc.wordpress.com 


\section{La continuidad de EU en la región (comercio e inversiones)}

La superpotencia norteamericana, durante el periodo que aborda este trabajo, se mantuvo presente geoeconómicamente como la más importante en la región, tal como pueden verse los montos de capitales realizados en exportaciones e importaciones. Lo remarcable en todos estos movimientos comerciales es que para los estadounidenses su primer socio comercial en la región fue México. Este dato es sumamente relevante tenerlo presente en el análisis de los apartados siguientes que conforman este trabajo, esto porque geoeconomía va de la mano con geopolítica.

\section{Exportaciones ALC-EU (millones de dólares)}

\begin{tabular}{|c|c|c|c|c|c|c|c|c|}
\hline 2000 & 2001 & 2002 & 2003 & 2004 & 2005 & 2006 & 2007 & 2008 \\
\hline $198,575.4$ & $188,929.7$ & $194,710.6$ & 204,706 & $189,361.9$ & $177,201.8$ & 312,887 & $326,408.4$ & $356,376.7$ \\
\hline 2009 & 2010 & 2011 & 2012 & 2013 & 2014 & 2015 & 2016 & 2017 \\
\hline $272,056.4$ & $347,550.2$ & $416,897.4$ & $431,980.2$ & $424,638.6$ & $431,864.6$ & $399,997.4$ & $391,299.6$ & $418,955.9$ \\
\hline
\end{tabular}

United States Census Bureau https://www.census.gov/foreign-trade/balance/c3570.html

\section{Exportaciones desde ALC-EU (en millones de dólares)}

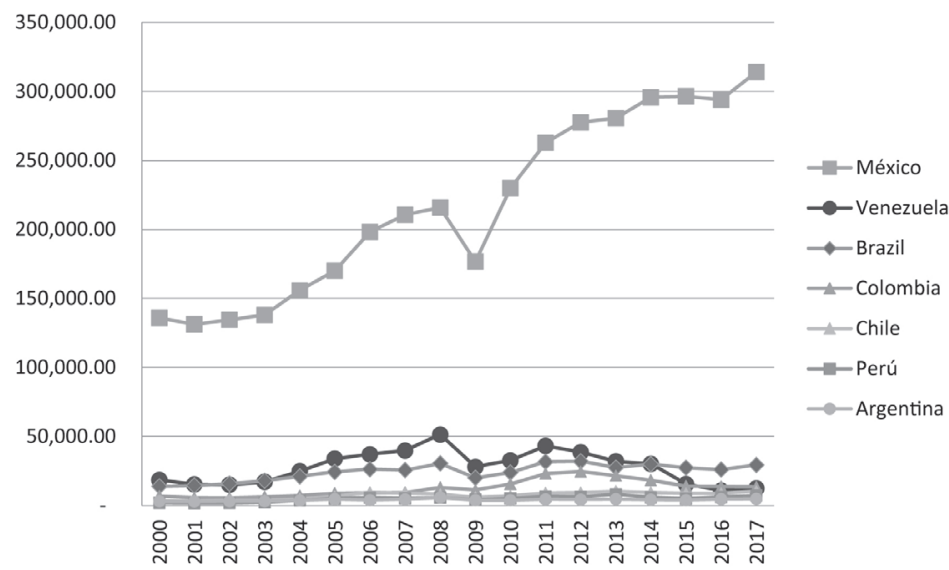

United States Census Bureau https://www.census.gov/foreign-trade/balance/c3570.html

Importaciones ALC-EU (millones de dólares)

\begin{tabular}{|c|c|c|c|c|c|c|c|c|}
\hline 2000 & 2001 & 2002 & 2003 & 2004 & 2005 & 2006 & 2007 & 2008 \\
\hline 158,705 & $147,754.7$ & $137,293.5$ & $137,433.5$ & $189,361.9$ & $177,201.8$ & $204,178.7$ & $222,489.6$ & $263,884.4$ \\
\hline 2009 & 2010 & 2011 & 2012 & 2013 & 2014 & 2015 & 2016 & 2017 \\
\hline $219,558.4$ & $279,651.7$ & $343,703.8$ & $375,675.8$ & $385,468.2$ & $398,794.7$ & $365,015.4$ & $342,719.7$ & $368,681.6$ \\
\hline
\end{tabular}

United States Census Bureau https://www.census.gov/foreign-trade/balance/c3570.html 
Importaciones desde ALC-EU (en millones de dólares)

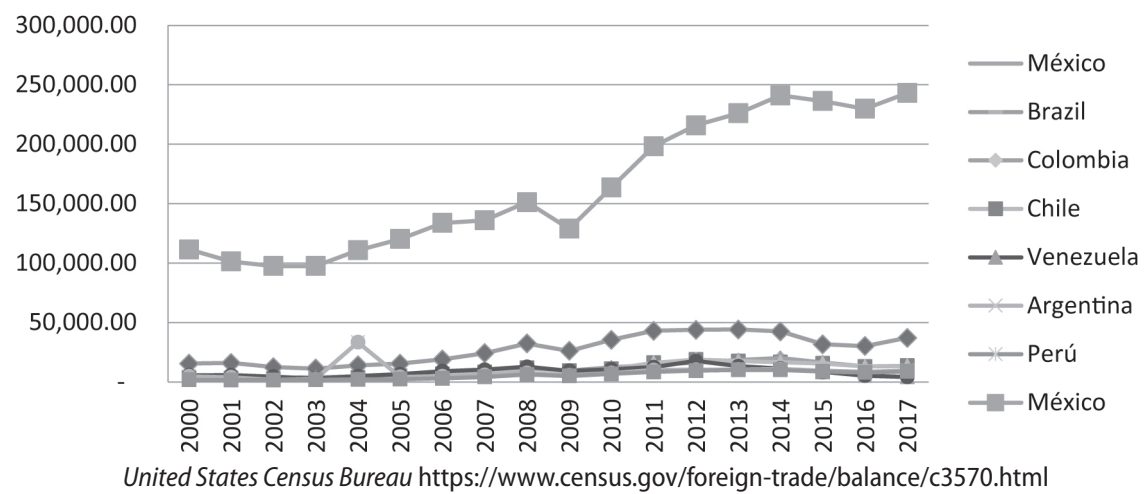

También en inversiones la superpotencia estadounidense sigue siendo la más importante en la región y México se mantiene como el socio más importante, seguido de Brasil y Chile.

Inversión extranjera directa EU-ALC (millones de dólares)

\begin{tabular}{|c|c|c|c|c|c|c|c|}
\hline 2009 & 2010 & 2011 & 2012 & 2013 & 2014 & 2015 & 2016 \\
\hline 216,117 & 233,649 & 247,141 & 261,688 & 236,480 & 233,172 & 221,021 & 228,143 \\
\hline
\end{tabular}

United States Census Bureau https://www.census.gov/foreign-trade/balance/c3570.html

Inversión extranjera directa de Estados Unidos en América Latina (millones de dólares)

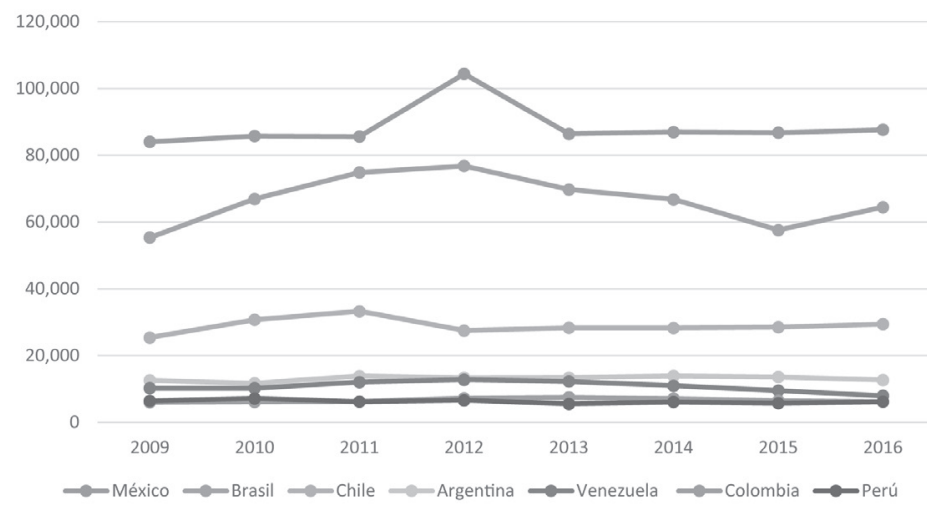

United States Census Bureau https://www.census.gov/foreign-trade/balance/c3570.html

En estos cuadros y gráficas se pueden visualizar la permanencia geoeconómica de la superpotencia norteamericana en la región y la nítida articulación geoeconómica de México con ella. Esta vinculación de México con la superpotencia 
norteamericana le permitirá mantener e impulsar una dinámica norte-sur en el seno de la región.

\section{La presencia de China en la región y el proyecto de un orden mundial euroasiático}

La potencia regional-global y segunda potencia económica mundial sentó decididamente su presencia en ALC desde inicios de los años 2000, justo cuando los gobiernos progresistas comienzan a difundirse en Sudamérica, Centroamérica y el Caribe. A inicios de los años 2000 China ya era una potencia regional consolidada e iniciaba su despliegue en varias regiones del mundo (Asía Pacífico, África y ALC).

\subsection{Presencia política y cooperación}

En el cuadro que sigue podemos apreciar la importancia geopolítica que le atribuyeron a la región, pues el número de viajes que realizaron tanto los presidentes como los vicepresidentes fue remarcable. Los viajes se realizaron desde el año 2001 hasta el año 2016, es decir cubrieron todo el periodo de florecimiento de los gobiernos progresistas.

Viajes de presidentes y autoridades de china a ALC 2001-2016

\begin{tabular}{|l|c|l|l|}
\hline Países ALC & $\begin{array}{c}\text { No. de } \\
\text { visitas }\end{array}$ & \multicolumn{1}{|c|}{ Autoridades chinas } & \multicolumn{1}{c|}{ Años } \\
\hline Chile & 7 & $\mathrm{JZ}, \mathrm{HJ}, \mathrm{HJ}, \mathrm{XJ}(\mathrm{vp}), \mathrm{WJ}(\mathrm{pm}), \mathrm{LK}(\mathrm{pm}), \mathrm{XJ}$ & $2001,2004,2010,2011,2012,2015,2016$ \\
\hline Brasil & 6 & $\mathrm{JZ}, \mathrm{HJ}, \mathrm{HJ}, \mathrm{WJ}(\mathrm{pm}), \mathrm{XJ}, \mathrm{LK}(\mathrm{pm})$ & $2001,2004,2010,2012,2014,2015$ \\
\hline Cuba & 6 & $\mathrm{JZ}, \mathrm{HJ}, \mathrm{HJ}, \mathrm{XJ}(\mathrm{vp}), \mathrm{XJ}, \mathrm{LK}(\mathrm{pm})$ & $2001,2004,2008,2011,2014,2016$ \\
\hline Argentina & 4 & $\mathrm{JZ}, \mathrm{HJ}, \mathrm{WJ}(\mathrm{pm}), \mathrm{XJ}$ & $2001,2004,2012,2014$ \\
\hline México & 3 & $\mathrm{JZ}, \mathrm{HJ}, \mathrm{XJ}$ & $2002,2005,2013$ \\
\hline Perú & 3 & $\mathrm{HJ}, \mathrm{LK}(\mathrm{pm}), \mathrm{XJ}$ & $2008,2015,2016$ \\
\hline Uruguay & 3 & $\mathrm{JZ}, \mathrm{XJ}(\mathrm{vp}), \mathrm{WJ}(\mathrm{pm})$ & $2001,2011,2012$ \\
\hline Venezuela & 3 & $\mathrm{JZ}, \mathrm{HJ}(\mathrm{pm}), \mathrm{XJ}$ & $2001,2010,2014$ \\
\hline Costa Rica & 2 & $\mathrm{HJ}, \mathrm{XJ}$ & 2008,2013 \\
\hline Colombia & 1 & $\mathrm{LK}(\mathrm{pm})$ & 2015 \\
\hline Ecuador & 1 & $\mathrm{XJ}$ & 2016 \\
\hline $\begin{array}{l}\text { Trinidad y } \\
\text { Tobago }\end{array}$ & 1 & $\mathrm{XJ}$ & 2013 \\
\hline \multicolumn{2}{|l}{ JZ-Jiang Zemin (P) HJ-Hu Jintao (P) XJ-Xi Jinping (P) } \\
\hline \multicolumn{2}{l}{ WJ-Wen Jiabao(PM) LK-Li Keqiang (PM) XJ-Xi Jinping (VP) } \\
\hline
\end{tabular}

Elaboración propia con datos de periódicos (La Jornada, El País, Milenio) en el periodo del 2001 al 2016. 
Como resultado de estos viajes y visitas diplomáticas se firmaron un número importante de acuerdos de cooperación bilateral y algunos tratados de libre comercio. Pero, quizá lo más sobresaliente llegó en Brasil el año 2014, en plena realización de la VI Cumbre BRICS, cuando el Presidente Xi Jinping anunció el acuerdo para la creación del Foro CELAC-China y la realización de su primera reunión ministerial para el año siguiente. De esta manera, en enero del año 2015 en China se plasmó la Primera Reunión Ministerial del Foro CELAC-China y se elaboró el Plan de Cooperación CELAC-China (2015-2019). Este proceso, después de unos años, ya en pleno en el proceso conservador y neoliberal, trató de continuar su impulso con la ejecución de la Segunda Reunión Ministerial del Foro CELAC-China en enero del año 2018, donde se aprobó el Plan de Acción Conjunto de Cooperación en Áreas prioritarias China-CELAC (2019-2021). Este Plan de Acción sigue vigente, pero quedan muchas dudas respecto de su implementación.

Acuerdos de Cooperación y TLC China-ALC

\begin{tabular}{|l|l|l|}
\hline \multicolumn{1}{|c|}{ PAÍS } & \multicolumn{1}{|c|}{ ACUERDOS DE COOPERACIÓN } & $\begin{array}{c}\text { TRATADOS DE LIBRE } \\
\text { COMERCIO }\end{array}$ \\
\hline Argentina & $2012,2013,2014(19), 2015(15), 2017(21)$ & \\
\hline Brasil & $2014,2015(35), 2017(14)$ & Negociación \\
\hline Colombia & $2012(11), 2015(12), 2017$ & \\
\hline Cuba & $2014(29), 2012(12)$ & 2010 \\
\hline Costa Rica & 2013 & 2006 \\
\hline Chile & $2014,2015(10)$, Chile (11) & \\
\hline Ecuador & $2011,2014,2016(12)$ & 2009 \\
\hline México & $2013(12)$ & \\
\hline Perú & $2014,2015(10)$ & \\
\hline Uruguay & $2013(20)$ & \\
\hline Trinidad y Tobago & 2013 & \\
\hline Venezuela & $2005(19), 2013,2014(38), 2015$ & \\
\hline
\end{tabular}

Elaboración propia con datos de las páginas oficiales de los gobiernos.

\subsection{Presencia financiera}

También China ha sentado su presencia financiera por medio de préstamos de Bancos Chinos a un grupo importante de países de la región, como se puede observar en el cuadro que sigue. Ahora bien, está presencia de los bancos chinos en 
la región, viene acompañada de la incursión de las empresas chinas en diversos sectores económicos.

Financiamientos de bancos chinos (BDC y Banco Ex-Im) a países de América Latina y el Caribe 2005-2017 (Millones de dólares)

\begin{tabular}{|l|c|c|}
\hline \multicolumn{1}{|c|}{ País } & No. de préstamos & Total (mdd) \\
\hline Venezuela & 17 & 62,200 \\
\hline Brasil & 12 & 42,100 \\
\hline Ecuador & 13 & 17,400 \\
\hline Argentina & 11 & 18,200 \\
\hline Bolivia & 10 & 3,500 \\
\hline Trinidad y Tobago & 2 & 2,600 \\
\hline Jamaica & 11 & 2,100 \\
\hline México & 1 & 1,000 \\
\hline Costa Rica & 1 & 395 \\
\hline Barbados & 1 & 170 \\
\hline Guyana & 2 & 175 \\
\hline Bahamas & 2 & 99 \\
\hline Perú & 2 & 478 \\
\hline
\end{tabular}

Fuente: China Statistical Yearbook. http://www.stats.gov.cn/tjsj/ndsj/2014/indexeh.htm

\subsection{La presencia comercial (comercio e inversiones)}

El comercio de china con la región que prácticamente era muy bajo en el año 2000, a lo largo de los años siguientes aumentará significativamente, como puede verse en los cuadros de exportaciones e importaciones comerciales. Y también en el dominio comercial sucedió algo digno de ser subrayado: Brasil fue el primer socio comercial con China (seguido de Chile) y, en consecuencia, el país latinoamericano y potencia regional en buenas relaciones geopolíticas con el coloso de Asia Pacífico.

\section{Exportaciones ALC-China}

\begin{tabular}{|c|c|c|c|c|c|c|c|c|}
\hline 2000 & 2001 & 2002 & 2003 & 2004 & 2005 & 2006 & 2007 & 2008 \\
\hline $5,360.03$ & $6,652.72$ & $8,248.7$ & $14,711.16$ & $21,638.86$ & $26,348.74$ & $33,575.53$ & $50,736.59$ & $71,181.28$ \\
\hline 2009 & 2010 & 2011 & 2012 & 2013 & 2014 & 2015 & 2016 & \\
\hline $64,073.18$ & $90,905.21$ & $120,207.22$ & $124,399.71$ & $126,129.04$ & $125,274.25$ & $102,476.95$ & $101,938.05$ & \\
\hline
\end{tabular}

Fuente: The Inter-American Dialogue 


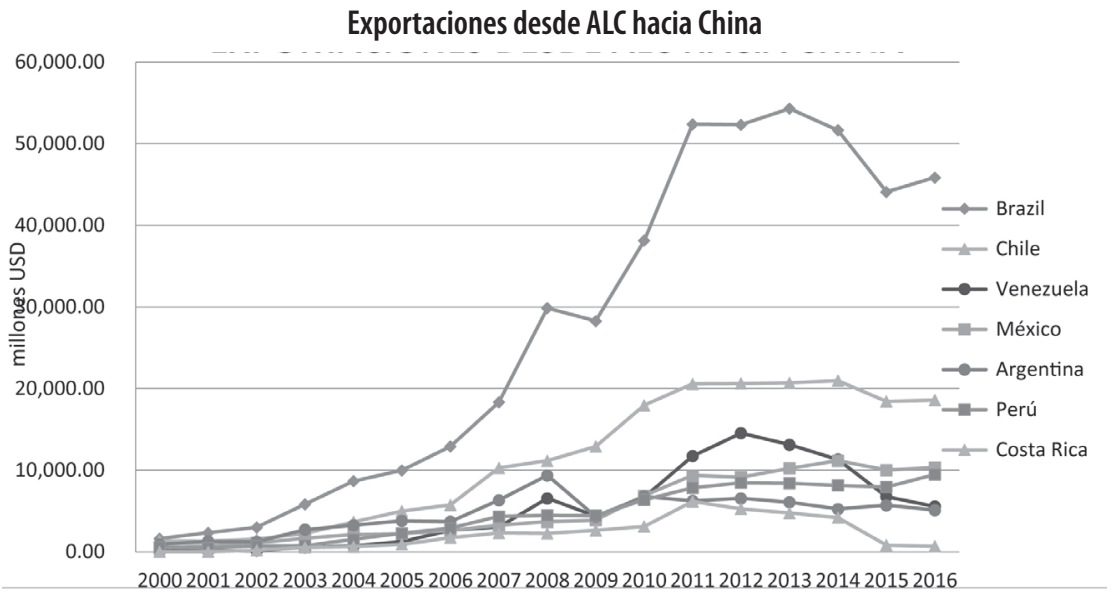

Fuente: China Statistical Yearbook http://www.stats.gov.cn/tjsj/ndsj/2014/indexeh.htm

Importaciones ALC-China

\begin{tabular}{|c|c|c|c|c|c|c|c|c|}
\hline 2000 & 2001 & 2002 & 2003 & 2004 & 2005 & 2006 & 2007 & 2008 \\
\hline $6,747.23$ & $7,753.22$ & $8,908.12$ & $11,020.32$ & $17,126.22$ & $22,269.59$ & $34,551.27$ & $48,903.89$ & $68,316.49$ \\
\hline 2009 & 2010 & 2011 & 2012 & 2013 & 2014 & 2015 & 2016 & \\
\hline $53,824.7$ & $77,407.05$ & $102,907.07$ & $129,663.5$ & $129,588.66$ & $130,653.34$ & $125,275.08$ & 109.031 .21 & \\
\hline
\end{tabular}

Fuente: China Statistical Yearbook http://www.stats.gov.cn/tjsj/ndsj/2014/indexeh.htm

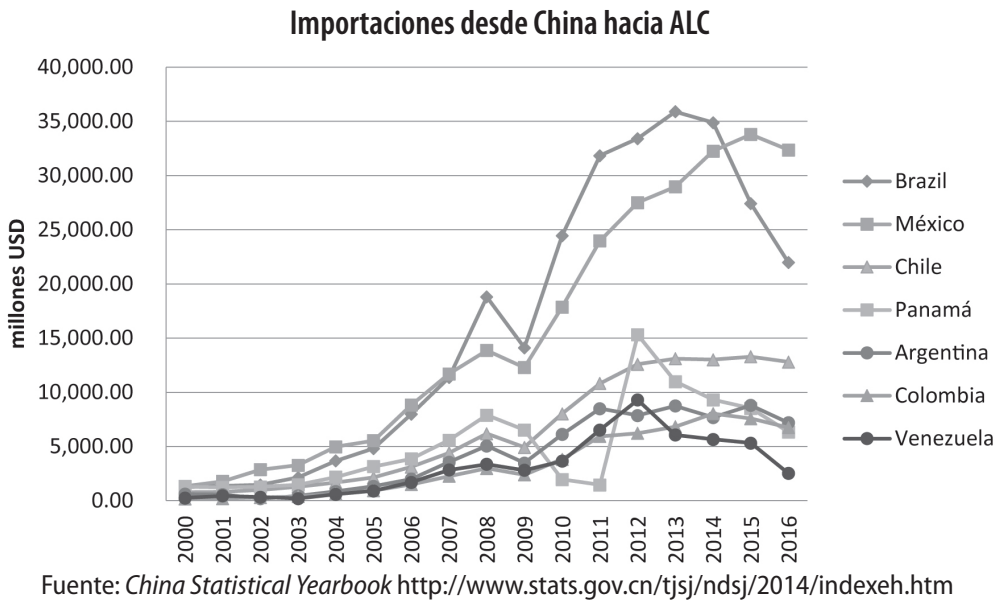

Como ya lo hemos anotado, geoeconomía implica geopolítica, en consecuencia la geopolítica de Brasil iba de la mano con la geopolítica China, pues como ya es obvio a estas alturas ambos países eran miembros del BRICS. Se puede anotar 
que la vinculación importante de la geoeconomía-geopolítica de Brasil con China produce e impulsa una dinámica sur-sur que afecta a toda la región.

\section{La región en el contexto de la apuesta de orden occidental y unipolar (1990-1999)}

Antes de avanzar, es crucial anotar que a inicios de los años ochenta, se produjo un giro geopolítico histórico en las políticas exteriores de los dos Estados semiperiféricos más importantes de la región: por un lado, Brasil terminó su alineamiento geopolítico con el orden occidental y los Estados Unidos y empezó un camino más independiente, nacional, autónomo y comenzó a mirar su entorno regional latinoamericano; por otro lado. México abandona progresivamente su postura nacionalista, independentista y autonomista para asumir la estrategia de la interdependencia, el americanismo, el alineamiento geopolítico con el orden occidental, la alianza estratégica con EU y el distanciamiento con su entorno regional latinoamericano. (Rocha y Morales, 2008)

A pesar de estos cambios iniciales, la región se mantiene vinculada al ensayo de orden unipolar occidental, vincula al orden continental americasno y atada a la geopolítica y geoeconomía de la superpotencia estadounidense, lo que implica que el neoliberalismo y Consenso de Washington se encuentran a la orden del día. En estos momentos, la generalidad de gobiernos latinoamericanos y caribeños son de orientación neoliberal y pro-estadounidenses; también se gestó en Estados Unidos la primera iniciativa neopanamericana, que nos amenazó con integrarnos subordinadamente en una dinámica continental estadounidense, neoliberal y comercial; recordemos las Cumbres de las Américas, los proyectos para crear un ALCA y el alineamiento subordinado de los gobiernos neoliberales de toda la región. Durante estos años los modelos económicos neoliberales se muestran inviables y hacen crisis. El neoliberalismo siempre significó subordinación geopolítica, involución económica y regresión en el bienestar social general. Y ¿por qué? Por la sencilla razón de que los gobiernos neoliberales fomentan el oligarquismo, es decir, la transferencia y concentración de riqueza por todos los medios (vía mercado y vía Estados) en manos de las oligarquías, lo que produce el empobrecimiento de las grandes mayorías; además de que estos gobiernos no propician el fortalecimiento del sector productivo, sino que les importa la extracción, la especulación y la renta (son colonialistas de sus propios países). Así pues, el oligarquismo es el engendro del neoliberalismo; toda la economía política del neoliberalismo en las periferias y 
semiperiferaias capitalistas está orientada a generar el oligarquismo. (Gilbert, 1996) (Peña, 2003) (Emmeerich, 2009).

Gobiernos progresistas y neoliberales en ALC 1990-1999

\begin{tabular}{|l|l|}
\hline Neoliberales & Progresistas \\
\hline Brasil & Cuba \\
\hline México & Costa Rica (94-98) \\
\hline Argentina & Venezuela (99) \\
\hline Chile & Ecuador (90-92) \\
\hline Venezuela & Belice (90-93; 98-99) \\
\hline Colombia & Jamaica \\
\hline Perú & Granada (90-95) \\
\hline Uruguay & \\
\hline Costa Rica (90-94) & \\
\hline Ecuador & \\
\hline Panamá & \\
\hline Guatemala & \\
\hline Paraguay & \\
\hline Bolivia & \\
\hline Honduras & \\
\hline El Salvador & \\
\hline República Dominicana & \\
\hline Haití & \\
\hline Nicaragua & \\
\hline Belice (93-98) & \\
\hline Granada (95-99) & \\
\hline
\end{tabular}

Elaboración propia.

Es por ello que, durante toda esta década, las luchas de los movimientos sociales se encuentran a la orden del día y las sociedades civiles de la región se dinamizan. En ese contexto, las izquierdas critican la estrategia de la revolución armada y el modelo de socialismo real (autoritario por cierto), esto es, las izquierdas se vuelven moderadas, optan por una vía de cambios y transformaciones dentro del sistema, asumen progresivamente un modelo de socialismo democrático e incursionan como partidos y coaliciones en los sistemas democráticos representativos. Estas 
izquierdas apuestan por el desarrollo sostenible, el bienestar general, la democracia participativa y el ideal de justicia social (combate de la pobreza y la desigualdad). A esto se le llamará progresismo, un poco más tarde.

\section{La región en el contexto del naciente orden euroasiático mundial (2000-2015)}

En estos años la región tiende a vincularse al proceso del naciente orden euroasiático mundial y, especialmente, al auge del RIC y, en particular, de China; esto es tiende a relacionarse con el "powert shift en la dirección de Asia" (Tokatlian, 2011) o la"masiva redistribución de poder del Oeste hacia el Este y del Norte hacia el Sur" (Takatlian, 2012b). En general, lo que viene de Euro-Asia y de Asia Pacífico es una influencia desarrollista, industrialista, nacionalista y estatista moderada, muy a contracorriente del neoliberalismo que se practica hasta el absurdo en Occidente; recordemos este proceso extraordinario en Asia Pacíico, impulsado primero por los llamados Países Dragones (donde Corea del Sur es el ejemplo paradigmático) y luego por los Países Tigres (donde China es el otro ejemplo paradigmático. (Marchini, 2012)

En este contexto de crisis del neoliberalismo globalizante o de la globalización neoliberal, se originan, proliferan e instalan en la región los gobiernos progresistas.

Gobiernos progresistas y neoliberales en ALC 2000-2018

\begin{tabular}{|l|l|}
\hline Neoliberales & Progresistas \\
\hline Brasil $(00-02)$ & Brasil $(03-16)$ \\
\hline México & Argentina $(03-15)$ \\
\hline Argentina $(00-03)$ & Chile $(06-10 ; 14-18)$ \\
\hline Chile $(00-06 ; 10-14)$ & Venezuela \\
\hline Colombia & Uruguay $(05-18)$ \\
\hline Perú & Cuba \\
\hline Uruguay $(00-05)$ & Costa Rica $(14-18)$ \\
\hline Costa Rica $(00-14)$ & Ecuador $(03-17)$ \\
\hline Ecuador $(00-03)$ & Panamá $(04-09)$ \\
\hline Panamá $(00-04 ; 09-18)$ & Guatemala $(08-12)$ \\
\hline Guatemala $(00-08 ; 12-18)$ & Paraguay $(08-12)$ \\
\hline Paraguay $(00-08 ; 12-18)$ & Bolivia $(06-18)$ \\
\hline
\end{tabular}




\begin{tabular}{|l|l|}
\hline Bolivia (00-06) & Honduras (06-09) \\
\hline Honduras (00-06;09-18) & El Salvador (09-18) \\
\hline El Salvador (00-09) & República Dominicana $(04-12 / 12-18)$ \\
\hline República Dominicana (00-04) & Haití (11-18) \\
\hline Haití (00-11) & Nicaragua (07-18) \\
\hline Nicaragua (00-07) & Jamaica (00-07; 12-16) \\
\hline Belice & \\
\hline Jamaica $(07-12 ; 16-18)$ & \\
\hline Granada & \\
\hline
\end{tabular}

Elaboración propia.

En general, todos estos gobiernos progresistas (con sus diferentes matices) disponen de las siguientes características:

- Cuentan con el apoyo de movimientos sociales y bases populares muy amplias;

- Fueron elegidos por medio de elecciones democráticas;

- Son gobiernos desarrollistas, industrializantes y nacionalistas moderados. Su debilidad fue haberse apoyado mucho en un modelo minero extractivista y agrícola exportador, seducidos por los precios altos de las commodities, lo que implicó relegar el proyecto original;

- Sus políticas públicas sociales apuntalaron el combate de la pobreza y la desigualdad social, por medio de la inversión en educación, salud, vivienda, salario, es decir, la promoción del bienestar social;

- Sus políticas públicas socio-culturales iniciales de defensa y promoción de los pueblos originarios;

- Sus primeras iniciativas en defensa del medio ambiente;

- Sus políticas exteriores comenzaron a distanciarse relativamente de la superpotencia norteamericana con la finalidad de reorientarse hacia Asia Pacífico, China, Rusia, India y Sudáfrica en una perspectiva geopolítica SurSur. El país líder de este giro geopolítico fue Brasil, como potencia regional y bajo el liderazgo del entonces presidente Lula da Silva. Bien entendido, Brasil ya había integrado el Foro BRICS. 
En el siguiente gráfico se puede observar la dinámica positiva de los principales países con gobiernos progresistas entre el núcleo países de la resistencia neoliberal (México, Colombia y Perú).

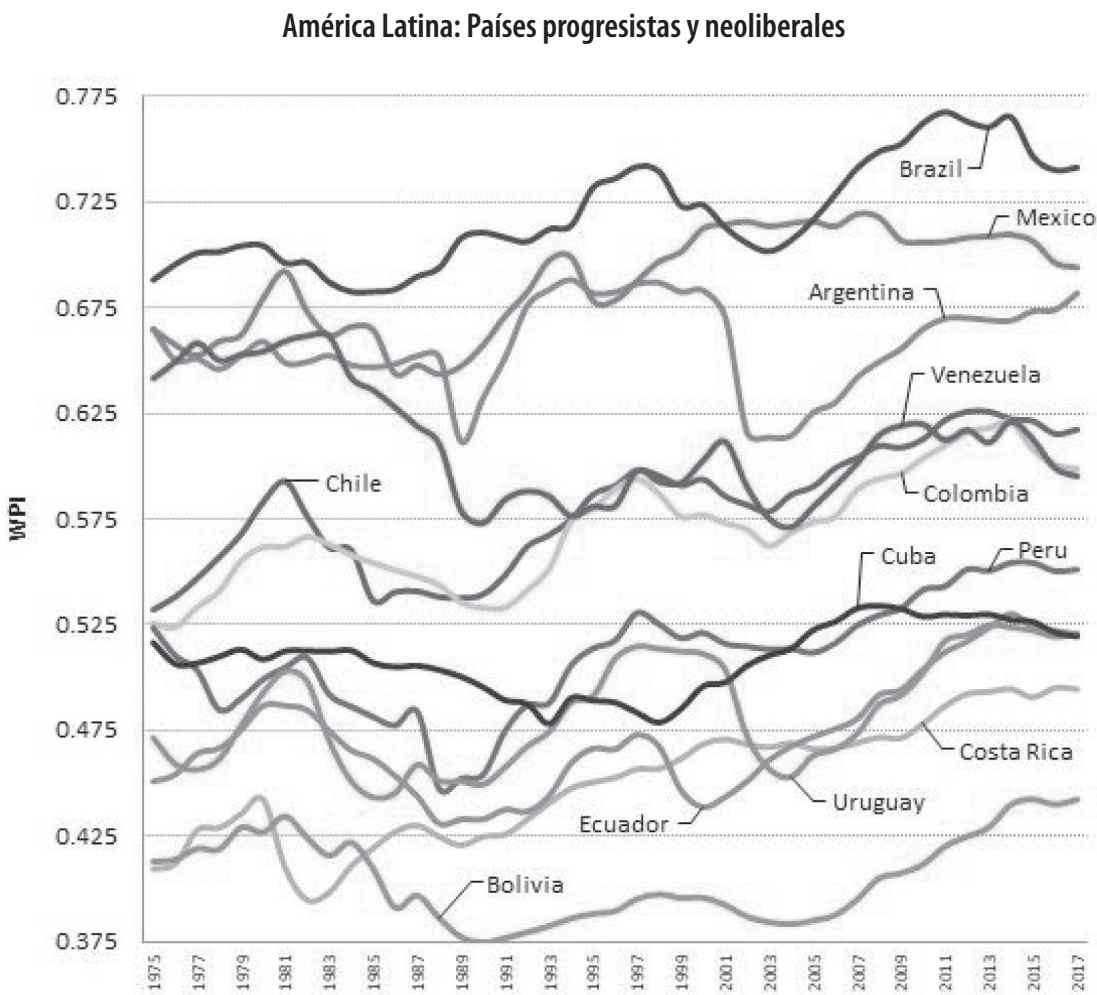

Fuente: Base de datos para el Índice de Poder Mundial. https://wordpress.com/view/integraciongobernabilidadydesarrolloalc.wordpress.com

En particular, un grupo de países resistieron y mantuvieron vinculados al ensayo de orden occidental unipolar, alineados y en alianza con los EE.UU. e integrantes de la órbita neoliberal y de la globalización neoliberal. En este grupo de países el núcleo duro estuvo conformado por México, Colombia, Perú, Honduras y Guatemala. México como potencia regional fue el líder de estos países.

En este contexto, es importante subrayar la cuestión de la tensión regional causada por las geopolíticas opuestas de las dos potencias regionales: México impulsando una geopolítica hacia el norte norteamericano y estadounidense y Brasil promoviendo una geopolítica hacia el sur euroasiático y pacífico asiático. Esta tensión estuvo presente durante los 15 años de hegemonía del progresismo. 
Aquí se plantea una pregunta: ¿en cuánto esta tensión geopolítica-geoeconómica dificultó el mejor despliegue de la región y su mayor articulación con Asía Pacífico y Euro-Asia? Esta dificultad fue un obstáculo para la configuración del orden regional latinoamericano-caribeño de acuerdo con el naciente orden internacional de Asía Pacífico y Euro-Asia.

Indudablemente, la reorientación geoeconómica y geopolítica de los Estados con gobiernos progresistas permitió un avance importante en el proceso de integración regional:

- Algunos procesos de integración existentes se dinamizaron: la CARICOM, el SICA, la AEC, el MERCOSUR y la ALADI; otros procesos de integración hicieron crisis debido a la práctica de un bilateralismo exacerbado (CAN y G3):

- Se crearon nuevos procesos de integración: la ALBA, la UNASUR, el PPP/ Proyecto Mesoamericano, la CELAC y la AP;

- Con la CELAC se armó un bosquejo de gobernabilidad/gobernanza en la región, nunca antes experimentado, puesto que proporcionó unidad y autonomía a toda región;

- Este bosquejo de gobernabilidad/gobrernanza se estructuró de la siguiente manera:

- En la cúspide la CELAC;

- En el segundo plano los dos proceso mesoregionales: El Foro de Tuxtla Gutierres-Proyecto Mesoamericano y la UNASUR

- $\quad$ En el tercer plano el MERCOSUR, la CARICOM, el SICA, la AEC, la CAN, la ALBA y la AP;

- En el cuarto plano los acuerdos bilaterales diversos.

- Habría que anotar que con este bosquejo de gobernabilidad/gobernanza se generó un dinamización regional (interna y externa) sin precedentes: la dinamización interna fue impulsada por las cumbres presidenciales, las reuniones ministeriales sectoriales, las reuniones de autoridades y las reuniones de otros actores en toda la región. La dinamización externa fue promovida por una geopolítica sur-sur, es decir relaciones de la región con los países del Grupo BRICS (sobre todo con China) y otros; y también por una geopolítica sur-norte, esto es la región con la UE. (Rocha, 2018)

Y es así como los gobiernos progresistas (mayoritarios en la región, entre los años 2000, 2015), el avance en el proceso de integración regional y la constitución de un bosquejo de gobernabilidad/gobernanza contribuyeron en el aumento 
sustantivo de la unidad y autonomía de la región. La unidad se tejía en las cumbres presidenciales y ministeriales (y otras instancias) y la autonomía se mostraba con el aumento de las capacidades regionales (la región cobró importancia económica, se hizo visible políticamente y atractiva culturalmente), subregionales (los esquemas de integración subregional avanzaron y fortalecieron) y nacionales (los Estados con gobiernos progresistas ascendieron e incluso otros con gobiernos conservadores y neoliberales). Es de esta manera como comienza a configurarse el nuevo orden regional latinoamericano y caribeño. En este contexto, el rol jugado por Brasil como potencia regional fue extraordinario, pues fue el país que impulsó la región hacia lo alto en todos los aspectos, pues la potencia regional reflexionó sobre la importancia de la unidad regional, integración regional y subregional, autonomía, desarrollo y crecimiento económico, bienestar social, avance tecnológico y científico. Además esta potencia regional presentó y representó a la región en los foros más importantes del mundo, pues su membresía BRICS le proporcionaba una importancia de país semiperiférico y potencia regional ascendente. Era Brasil la potencia regional que llevaba de la mano a toda región hacia Asia Pacífico, esto es hacia el acoplamiento con el nuevo orden mundial emergente. (Schnake, 2010).

\section{ALC en el mundo multipolar emergente (2016...)}

¿Qué ha ocurrido en nuestra región desde el año 2016 hasta ahora? En general, desde los EE.UU, en alianza con los nuevos gobiernos neoliberales y conservadores, se ha implementado una intervención creciente para desactivar el orden regional naciente que fue impulsado por los gobiernos progresistas y que buscaba la conexión con Asia Pacífico y Euro-Asia (el orden mundial emergente). Veamos esto.

- Por un lado:

- El restablecimiento mayoritario de un neoliberalismo conservador (Brasil, Argentina, Chile, Honduras, Paraguay, Perú, Colombia, Ecuador, El Salvador...), mediante procesos electorales, golpes de Estado disimulados (Brasil, Paraguay, Honduras...) y el uso de métodos diversos (visibles e invisibles);

- Una rearticulación subordinada de los países con gobiernos conservadores y neoliberales con la superpotencia declinante de Norteamérica; donde el ejemplo claro e impactante es el de Brasil (con un giro geopolítico de 180 grados, casi al nivel plano del entreguismo), aunque también Colombia no deja de seguir este mal ejemplo (permitiendo el establecimiento de siete 
bases militares y promoviendo el intervencionismo del país vecino), sin olvidar el rol servil de los actuales gobiernos de Argentina y Chile;

- La formación del Grupo de Lima (grupo de gobiernos conservadores y neoliberales) liderado por Brasil y Argentina, muy afín a la política exterior de los Estados Unidos y a la política continental (retro) neopanamericana de la OEA y su peón de turno en la Secretaría General (el nefasto señor Almagro). Dicho sea de paso el Grupo de Lima no es legítimo en el concierto regional latinoamericano-caribeño;

- La desactivación de la CELAC y de la UNASUR, promovida por los gobiernos conservadores del Grupo de Lima con la finalidad de desactivar el proceso de unidad y autonomía de la región y desvincular su dinámica regional orientada hacia Asia Pacífico. El Grupo de Lima se constituyó al margen de la institucionalidad regional latinoamericana-caribeña, contra su dinámica regional interna (de cohesión y fortalecimiento) y externa (de autonomía y proyección internacional). De esta manera, el Grupo de Lima se constituyó en caja de resonancia de la política exterior de la superpotencia en declive, en apéndice de la OEA y elemento reactivador de ésta (recordemos su pérdida de vigencia temporal). Es esta OEA retro-neo-panamericana donde se ha desempolvado la llamada Doctrina Monroe del "patio trasero):

- La hostilización de los gobiernos progresistas, promoviendo golpes disimulados (parlamentarios), solapando fraudes electorales, amenazando a gobiernos, incitando la persecución judicial de sus líderes e, incluso, impulsando intervenciones políticas y militares (como en el caso de Venezuela). No está demás anotar la destitución de Dilma Rousseff y el encarcelamiento del ex Presidente Lula da Silva, el líder de los presidentes progresistas;

- $\quad$ El regreso de EU a la región, con la Doctrina Monroe en una mano y el garrote militar en la otra (instalando nuevas bases militares, realizando ejercicios militares y amenazando con el Comando Militar del Sur);

- ALC se encuentra nuevamente ante el regreso del neopanamericanismo de estilo trumpiano, esto es conservador, republicano, militarista y neomonroista.

Pero, tenemos que anotar, que lo más grave es la desactivación de la potencia regional sudamericana como resultado de la ejecución de una maniobra política en la cúspide del Estado para remplazar a la élite política progresista por una élite conservadora, neoliberal y pro-norteamericana. Aparentemente en todo este movimiento de remplazo brutal de una élite gubernamental por otra élite gubernamental solamente intervinieron fuerzas nacionales (élites políticas conservadoras y neoli- 
berales, élites militares y oligarquías empresariales), muy visibles por cierto; pero hay muchas evidencias de la intervención de fuerzas invisibles norteamericanas. Solamente dejo planteadas dos preguntas: ¿A quién le interesaba ese remplazo brutal de élite política gubernamental progresista, a las derechas brasileñas o a los EE.UU.? ¿Hasta qué punto se había irritado, por interferir en su geopolítica y geoestrategia, la superpotencia estadounidense declinante con la potencia regional ascendente?

- Por otro lado:

- El repliegue relativo de los gobiernos progresistas y su persistencia en tan solo países como Bolivia, Uruguay, Venezuela (con rasgos autoritarios), Nicaragua (también con matices autoritarios), sin olvidar Cuba (en pleno proceso de cambios), a los cuales habrá que sumar el nuevo gobierno progresista que ya se encuentra en plena actividad en México;

- Aquí posiblemente se plantea la pregunta sobre si el proceso progresista que ya se encuentra en curso en México establece una continuidad o marca una renovación respecto de la primera generación de gobiernos progresistas. Está claro que habrá que analizar la política interior y la política exterior de este nuevo gobierno progresista. Pero, se puede anotar que en política interna se está dejando de lado el neoliberalismo y que en política externa se han puesto por delante los principios de respeto de la soberanía nacional de los gobiernos, de no intervención en los asuntos de otros Estados y de autodeterminación de los pueblos.

En lo sustancial se han producido en la región dos sucesos de trascendental importancia histórica:

- Primero, después de 38 años, se acaba de producir un nuevo giro geopolítico en la región: Brasil vuelve a entablar una relación estratégica geopolítica con los Estados Unidos y el gobierno conservador de D. Trump y México toma distancia de la relación estratégica que estableció con la superpotencia desde inicios de los años noventa del siglo pasado. Brasil se subordina y alinea y México se autonomiza e independiza de los EE.UU. Este es el giro geopolítico de las potencias regionales (Brasil y México) que implica a toda la región. Esto es, la región tiende mayoritariamente a su vieja relación subordinada (geoeconómica y geopolíticamente) con los EE.UU.; esto es, vuelve a incorporarse al orden continental (neo) panamericano. Los presidentes conservadores J. Bolsonaro, M. Macri, I. Duque y S. Piñeira ocupan el escenario político y geopolítico regional. Además, todo parece indicar, por las políticas interna y externa en curso, que Brasil declinará, dejará de ser una potencia 
regional (o se convertirá en una potencia regional secundaria) y también se desvalorizará (¿perderá? su membresía en el BRICS; y México ascenderá y se fortalecerá como potencia regional, lo que le permitirá acentuar su liderazgo regional e internacional. ¿México un posible miembro del RICS?

- Segundo, la región se ha convertido en un espacio de disputa inter-hegemónica entre la superpotencia declinante y la potencia regional-global ascendente. EE.UU. está de vuelta a nuestra región después de que ha sufrido derrotas parciales en otras partes del mundo (Afganistán, Irak, Crimea, Siria, Asia Pacífico ...). Así pues, EE.UU. está en situación de repliegue en América Latina y el Caribe, lo que implica entrar a disputarle el terreno ganado a China en la región (y también a Rusia). Quedan muchas interrogantes planteadas. ¿Qué harán los gobiernos conservadores (de Brasil, Argentina, Chile, Ecuador, Perú, por ejemplo) ante la presencia de China en sus respectivos países? ¿Cortarán sus nexos geoeconómicos con China? Cierto, estamos pensando en Venezuela, pues la intervención política y militar que promueve el presidente estadounidense D. Trump contra este país, no es solamente porque el presidente Maduro es supuestamente un progresista autoritario y dictador que está sojuzgando a su pueblo; está muy claro que es sobre todo porque el país sudamericano y caribeño se encuentran presentes China y Rusia tanto económica como militarmente. Las razones superficiales encubren la razón de fondo. Y, lo más grave es que los gobiernos conservadores de la región se movilizan por las razones superficiales y EE.UU. lo hace por la razón de fondo.

En consecuencia, estos dos sucesos históricos condicionarán los procesos de la región y, por lo tanto, las posibilidades de desenvolvimiento de los gobiernos conservadores y de los gobiernos progresistas.

\section{A manera de conclusión}

Sobre ALC:

ALC siempre se mantuvo conectada al orden occidental particular durante la bipolaridad mundial (Cuba y la revolución socialista de 1959 fue una excepción). Durante los años ochenta, casi todos los gobiernos fueron de orientación neoliberal (Nicaragua y la revolución sandinista de 1979 fue la segunda excepción). Se puede 
anotar que ALC, además, fue incorporada al orden continental americano y panamericano organizado por los EE.UU. (Doctrina Monroe, OEA y TIAR). Esto es quedó sujetada doblemente. En los años noventa, la mayoría de los gobiernos neoliberales hicieron crisis políticas y económicas; pero, en el contexto de estos años, a la vez que la región se mantiene atada a la apuesta norteamericana de un orden occidental y unipolar y también al orden continental americano y panamericano, se gesta un proceso político progresista, impulsado por las luchas de los movimientos sociales populares y las izquierdas moderadas que buscaban una alternativa para salir del neoliberalismo. (Alcalde, 2010).

El proceso progresista se inició en Venezuela, pasando por Brasil, Argentina, Uruguay, Bolivia, Ecuador, etc, y luego se extendió por toda la región hasta finales del año de 2015. Durante estos 15 años los gobiernos progresistas lograron vincularse al proceso de constitución del orden euroasiático emergente. Brasil como potencia regional se integra en el BRICS y un buen grupo de países emprenden cercanas relaciones con China y Rusia. El proceso de integración regional, por medio de la CELAC, también, se articula con China (Foro China-CELAC) y finalmente China se asienta en la región. Durante estos años, se puede anotar, que en ALC se gestó la constitución de un orden regional propio y autónomo, fuertemente impulsado desde América del Sur. (Alcalde, 2010) (Tokatlian, 2001).

Es en este momento de crisis de los modelos extractivistas minero-petrolero y primario agrícola exportadores cuando las oligarquías conservadoras neoliberales y la intervención estadounidense se articulan y generan el proceso regresivo conservador. Así entonces, desde los años 2016 y 2017 se inicia el declive del progresismo, el restablecimiento del conservadurismo neoliberal y la rearticulación de la región con la superpotencia declinante. EU vuelve a desempolvar la Doctrina Monroe y su corolario imperialista del "patio trasero". Los gobiernos conservadores vuelven a incorporar a nuestra región al orden continental americano-(neo)panamericano. Pero, esta rearticulación de ALC con el orden continental americano-(neo)panamericano revela una grave problema. Hemos anotado que geoeconomía y geopolítica van de la mano, pero algo raro está sucediendo con los gobiernos conservadores y neoliberales de ALC: geopolíticamente se re-articulan con los EE.UU. y geoeconómicamente se mantienen articulados con China. Así, podemos decir que esta es la novedosa "esquizofrenia" de la que sufren los gobiernos conservadores-neoliberales de nuestra región y que conforman el Grupo de Lima.

En consecuencia, nuestra región se ha convertido en un espacio de disputa por la supremacía y la hegemonía entre la China ascendente y los EE.UU. declinantes. Venezuela es un buen ejemplo de lo que está sucediendo y podría suceder: inter- 
venciones económicas, políticas y militares en los países no alineados de la región; $y$, lo más grave, el control y dominio de toda la región. Lo que implicaría que la región quedaría atada relativamente al declive de la superpotencia, aunque posiblemente en algo vinculada a la China ascendente.

Sobre ALC en el mundo:

Después del fracaso del ensayo de un orden unipolar estadounidense y occidental, estamos experimentando en el sistema político internacional tiempos de multipolaridad y de competencia abierta entre grandes poderes estatales: EE.UU. y Alemania, por un lado y, por el otro lado, China, Rusia e India.

Multipolaridad significa competencia y conflicto abierto entre los grandes poderes estatales por la formación de un nuevo orden mundial, especialmente entre EE.UU., China y Rusia. ¿Se orienta el mundo hacia una bi-tri-multipolaridad? (Tokatlian, 2012a)

En este contexto multipolar, la tendencia global predominante apunta hacia Euro-Asia, Asia-Pacífico y China como nuevo centro del mundo capitalista, lo cual indicaría que estamos transitando de un mundo capitalista occidental a otra organización geoeconómica y geopolítica del mundo, esto es posiblemente un mundo capitalista oriental. ¿El desafío de América Latina es articularse a dicha tendencia global?

En consecuencia, por un lado, todos sabemos que los Estados Unidos tratarán de renovarse como centro del mundo capitalista del siglo XXI y, muy posiblemente, buscarán aferrarse con todo en el continente americano y en nuestra región; y, por otro lado, China continuará con su expansión mundial y regional, incluyendo a nuestra región, donde ya está presente y muy bien establecida.

En dicho contexto la cuestión del lugar y rol de nuestra región en el nuevo orden mundial es una cuestión central, por ello para lograr preservar y fortalecer la autonomía geopolítica y geoeconómica regional es fundamental contar con gobiernos progresistas dispuestos a navegar inteligentemente en las aguas agitadas de las multipolaridad mundial con la brújula geopolítica bien arreglada en dirección Sur-Sur y hacia Asia Pacífico y el OBOR. 


\section{Bibliografía}

ALCALDE, J. (2010). El cambio de orden internacional y las perspectivas de un orden sudamericano. Pontificia Universidad Católica del Perú, 9, 1-44. Recuperado de: http:// repositorio.pucp.edu.pe/index/bitstream/handle/123456789/52667/cambio_perspectivas_alcalde.pdf?sequence $=1$ \&isAllowed $=y$

Centro de Estudios EstratéGICOS (2016). ¿Un nuevo orden mundial? Anepe, 8, 1-19. Recuperado de: https://www.anepe.cl/wp-content/uploads/newsletter-30-11-2016.pdf

DallaneGra, L. P. (2008). Tendencias polítcas en América Latina en el contexto mundial del siglo XXI: Hacia una teoría política realista-sistémica estructural sobre América Latina. Espiral, Vol. 25, No. 43. Guadalajara, México.

EMMERICH, N. (2009). La política exterior de Estados Unidos hacia América Latina en la nueva administración demócrata. Buenos Aires, Argentina. Universidad de Belgrano. No. 231,1-36. Recuperado de: https://www.academia.edu/2444595/La_politica_exterior_ de_Estados_Unidos_hacia_America_Latina_en_la_nueva_administracion_democrata GIlberT CeBAllos, J. (1997). América Latina y el nuevo orden internacional. Revista de Sociología, No. 11-12. doi:10.5354/0719-529X.1997.27696

Hedley, B. (2005). La Sociedad Anárquica. Madrid, España. Los Libros de La Catarata. HELD, D. (1997). La democracia y el orden global. Barcelona, España. Paidós Ibérica.

Huntington, S. P. (1996). El orden político en las sociedades en cambio. España. Paidós Estado y Sociedad, (Book, Whole), 1-25.

IKENBERRY, G. J. (2018). Globalización y orden político: los orígenes de la integración económica mundial y sus consecuencias. Colombia Internacional, (52), 5-24. Doi: https:// doi.org/10.7440/colombiaint52.2001.00

IKENBERRY,G. J. (1996). La estructuración del orden de las relaciones internacionales: perspectivas teóricas, históricas y comparativas. Regionalismo y poder en América: los límites del neorrealismo. Ciudad de México, México. Miguel Ángel Porrúa.

MARCHINI, G.(2012). Crecimiento económico y desarrollo financiero en Asia-Pacífico. Guadalajara, México. Centro Universitario de Ciencias Sociales y Humanidades.

MARCHINI, G.(2012). Crecimiento económico y desarrollo financiero en Asia-Pacífico. Guadalajara, México. Centro Universitario de Ciencias Sociales y Humanidades.

Moy, V. (2013). La inserción de las potencias regionales latino-americanas en la economía global y regional: el caso de México Valeria Moy. 9-18.

PEÑA, Lorenzo (2003). América Latina ante el nuevo orden mundial. PAL: 1-13. Recuperado de: http://www.unifr.ch/derechopenal/pal/pdf/actuel/pal5.pdf

RochA, A. (2018). La CELAC en el proceso de construcción de una región autónoma global. Dimensiones, estrategias y alternativas de la integración autónoma para América Latina 
y el Caribe, Desafíos para el caso Méxicano-2010 a 2015-. Tomo II: Política, Geopolítica y Ecología Política. Guadalajara, México: Universidad de Guadalajara.

RochA, A. (2018). Un ensayo de gobernabilidad autónoma regional en un contexto de gobernabilidad-gobernanza subregional. La dimensión político-institucional de los procesos de integración de américa latina (2000-2016). (Trabajo próximo a publicarse).

RoCHA \& Morales (2008). El Sistema Político Internacional de post-Guerra Fría y el rol de las potencias regionales-mediadoras, los casos de Brasil y México. Espiral. Vol. 15. No. 43. Guadalajara, México.

RUSSELL, R. \& TOKATLIAN, J. G. (2009). Modelos de política exterior y opciones estratégicas El caso de América Latina frente a Estados Unidos. Revista CIDOB d'Afers Internaionals, (85-86), 211-249. Recuperado de: http://www.udesa.edu.ar/files/UAHumanidades/ ARTICULOS/220509tokarussell.pdf

SCHNAKE GÁLVEZ, A. (2010). Orden multipolar en el siglo XXI: efeectos globales y regionales. Revista Encricujada Americana, 19-41.Doi: https://doi.org/0718-5766

TOKATLIAN, J. G., \& CARVAJAL, L. (1995). Autonomía y política exterior: un debate abierto, un futuro incierto. Afers Internaionals, (28), 7-31. Doi: https://doi.org/10.2307/40585561

TOKATLIAN, J. G. (2012). Crisis y redistribución del poder mundial. Crisis and Redistribution of World Power., (100), 25-41. Recuperado de: http://search.ebscohost.com/login.as px?direct=true $\& \mathrm{db}=$ fua $\& A N=86389607 \&$ lang $=e s \&$ site $=$ ehost-live

ToKATLIAN, J. G. (2001). El orden después de Irak. Nueva Sociedad, (102-114). Recuperado de: http://nuso.org/media/articles/downloads/3125_1.pdf

TOKATLIAN, J. G. (2011). Latinoamérica y sus opciones estratégicas: un análisis de las relaciones extraregionales. Análisis Político, 73, 139-158. Recuperado de: http://www.scielo.org. co/pdf/anpol/v24n73/v24n73a07.pdf

Tokatlian, J. G. (2012). Política Exterior: Un reordenamiento de América Latina. Centro de Pensamiento Estratégico-Ministerio de Relaciones Exteriores, (1-19). Recuperado de: https://www.cancilleria.gov.co/sites/default/files/pensamiento_estrategico/ documentos_sobre_region/a.Politica\%20Exterior,\%20Un\%20Reordenamiento\%20 en\%20America\%20Latina\%20-\%20Julio\%202012\%20-\%20Juan\%20TOKATLIAN.pdf

\footnotetext{
Alberto Rocha Valencia. Magíster y doctor en Sociología por la Universidad de París VIII, Francia. Docente del Departamento de Estudios Ibéricos y Latinoamericanos de la Universidad de Guadalajara. Correo electrónico: albertorochav@yahoo.com.mx
}

Recibido: julio 2019

Aprobado: septiembre 2019 
